\title{
PENGGUNAAN KAMUS BESAR BAHASA INDONESIA (KBBI) DALAM PEMBELAJARAN KOSAKATA BAKU DAN TIDAK BAKU PADA SISWA KELAS IV SD
}

\author{
Sulis Setiawati \\ Program Studi Pendidikan Bahasa dan Sastra Indonesia \\ Fakultas Bahasa dan Seni Universitas Indraprasta PGRI Jakarta \\ Jalan Nangka 58 Tanjung Barat, Jakarta Selatan, 12530 \\ Email:sulis2310@yahoo.co.id \\ Submitted :05-05-2016, Reviewed:30-05-2016, Accepted:31-10-2016 \\ http://dx.doi.org/10.22202/JG.2016.v2i1.1408
}

\begin{abstract}
Abstrak
Kamus adalah sebuah karya yang berfungsi sebagai referensi dan sumber belajar. Kamus pada umumnya berupa senarai kata yang disusun secara alfabetis. Selain itu, disertakan pula informasi mengenai ejaan, pelafalan, kelas kata, makna kata, kadangkala sejarah kata, dan contoh pemakaian kata dalam kalimat. Kamus Besar Bahasa Indonesia adalah salah satu sumber belajar yang dapat digunakan siswa dan guru dalam pembelajaran kosakata baku dan tidak baku.Ragam bahasa baku dapat dibatasi dengan beberapa sudut pandang, di antaranya: (1) sudut pandang kebakuan bahasa yang digunakan, (2) sudut pandang informasi, dan (3) sudut pandang pengguna bahasa.
\end{abstract}

Kata kunci: Kamus Besar Bahasa Indonesia (KBBI), Pembelajaran, Kosakata baku dan tidak baku

\begin{abstract}
Dictionary is a work that serves as a reference and learning resources. Dictionaries generally in the form of a list of words arranged alphabetically. In addition, also included information about the spelling, pronunciation, part of speech, the meaning of words, sometimes the history of the word and example of usage of the word in a sentence. Indonesian dictionary is a source of learning that can be used by students and teachers in learning basic vocabulary and not baku.Ragam standard language can be limited by several viewpoints, including: (1) the standpoint of kebakuan language used, (2) the angle view information, and (3) a user standpoint language. Keywords: Big Indonesian Dictionary (KBBI), Learning, Vocabulary standard and non-standard
\end{abstract}

\section{Pendahuluan}

Penggunaan Bahasa Indonesia yang baik dan benar telah menjadi keharusan. Pemerintah melalui Menteri Pendidikan dan Kebudayaan Republik Indonesia menurunkan Keputusan Nomor 0543a/U/1987 yang mendasari usaha penyempurnaan penggunaan ejaan bahasa Indonesia yang baik dan benar.

Bahasa Indonesia yang baik adalah bahasa yang digunakan sesuai situasi dan kondisi sedangkan bahasa Indonesia yang 
benar adalah yang sesuai dengan EYD. Tentu saja hal ini tidak dapat terealisasi tanpa adanya bimbingan dan pembiasaan. Pembiasaan sejak dini akan berimplikasi secara positif pada masa selanjutnya.

Dalam kurikulum 2013 untuk Sekolah Dasar, dalam hal ini kelas IV, siswa dituntut untuk dapat mengetahui sekaligus membedakan antara kosakata baku dan tidak baku disertai dengan pengetahuan makna kata tersebut. Informasi ini bisa mereka dapatkan dari Kamus Besar Bahasa Indonesia dengan bimbingan dan arahan guru.

Materi kosakata baku dan tidak baku selalu ada dalam tiap Kompetensi Dasar. Berikut adalah contoh deskripsinya:

\section{Kompetensi Dasar:}

3.1 Menggali informasi dari teks laporan hasil pengamatan tentang gaya, gerak, energi panas, bunyi, dan cahaya dengan bantuan guru dan teman dalam bahasa Indonesia lisan dan tulis dengan memilih dan memilah kosakata baku

3.2 Menguraikan teks instruksi tentang pemeliharaan pancaindera serta penggunaan alat teknologi modern dan tradisional dengan bantuan guru dan teman dalam bahasa Indonesia lisan dan tulis dengan memilih dan memilah kosakata baku

3.3 Menggali informasi dari teks wawancara tentang jenis-jenis usaha dan pekerjaan serta kegiatan ekonomi dan koperasi dengan bantuan guru dan teman dalam bahasa Indonesia lisan dan tulis dengan memilih dan memilah kosakata baku

3.4 Menggali informasi dari teks cerita petualangan tentang lingkungan dan sumber daya alam dengan bantuan guru dan teman dalam bahasa Indonesia lisan dan tulis dengan memilih dan memilah kosakata baku.

3.5 Menggali informasi dari teks ulasan buku tentang nilai peninggalan sejarah dan perkembangan Hindu-Budha di Indonesia dengan bantuan guru dan teman dalam bahasa Indonesia lisan dan tulis dengan memilih dan memilah kosakata baku
4.1 Mengamati, mengolah, dan menyajikan teks laporan hasil pengamatan tentang gaya, gerak, energi panas, bunyi, dan cahaya dalam bahasa Indonesia lisan dan tulis dengan memilih dan memilah kosakata baku

4.2Menerangkan dan mempraktikkan teks arahan/petunjuk tentang pemeliharaan pancaindera serta penggunaan alat teknologi modern dan tradisional dengan bantuan guru dan teman dalam secara mandiri dalam teks bahasa Indonesia lisan dan tulis dengan memilih dan memilah kosakata baku

4.3 Mengolah dan menyajikan teks ulasan buku tentang nilai peninggalan sejarah dan perkembangan Hindu-Buddha di Indonesia secara mandiri dalam bahasa Indonesia lisan dan tulis dengan memilih dan memilah kosakata baku

4.4 Menyajikan teks cerita petualangan tentang lingkungan dan sumber daya alam secara mandiri dalam teks bahasa Indonesia lisan dan tulis dengan memilih dan memilah kosakata baku.

4.5 Mengolah dan menyajikan teks ulasan buku tentang nilai peninggalan sejarah dan perkembangan Hindu-Buddha di Indonesia secara mandiri dalam bahasa Indonesia lisan dan tulis dengan memilih dan memilah

Namun, dalam praktiknya masih ada guru yang hanya mengandalkan buku paket dalam menjelaskan materi dengan mengabaikan sumber belajar yang lain seperti kamus, buku ejaan, pedoman istilah, dan lain-lain.

\section{Metode}

Penelitian ini merupakan penelitian kualitatif dengan metode deskriptif. Metode desktiptif adalah suatu metode dalam meneliti suatu kelompok manusia, suatu objek, suatu kondisi, suatu sistem pemikiran, ataupun suatu kelas peristiwa pada masa sekarang (Nazir, 2005:54). Penulis menggunakan metode penelitian ini karena penelitian ini bertujuan membuat deskripsi atau gambaran secara 
sistematis, faktual, dan akurat mengenai fakta-fakta yang diselidiki.

Data dikumpulkan dengan cara menganalisis, mengklasifikasi, dan mengevaluasi kosakata baku dan tidak baku yang terdapat dalam KBBI Pusat Bahasa Edisi Keempat. Kosakata yang dipilih adalah yang masih relevan digunakan untuk siswa SD kelas IV.

Penulis

mendeskripsikan

mencoba

bagaimana

pemanfaatan sumber belajar berupa kamus dapat digunakan dalam konteks pembelajaran kosakata baku dan tidak baku.

\section{Pembahasan}

\section{a. Kamus Besar Bahasa Indonesia (KBBI)}

Kata kamus adalah kata serapan dari bahasa Arab yaitu qamus. Kata qamus itu sendiri berasal dari kata dalam bahasa Yunani yaitu okeanos yang berarti 'lautan'. Dari sejarah kata kamus ini dapat diketahui bahwa makna dasar dari kata kamus yaitu sebagai wadah pengetahuan, khususnya pengetahuan bahasa .

Kamus adalah sebuah karya yang berfungsi sebagai referensi. Kamus pada umumnya berupa senarai kata yang disusun secara alfabetis. Selain itu, disertakan pula informasi mengenai ejaan, pelafalan, kelas kata, makna kata, kadangkala sejarah kata, dan contoh pemakaian kata dalam kalimat (Kushartanti dkk, 2009:223).

Sementara itu dalam KBBI (2008:xxv) disebutkan bahwa kamus merupakan sumber rujukan yang andal dalam memahami makna kata suatu bahasa karena kamus memuat perbendaharaan kata suatu bahasa, yang secara ideal tidak terbatas jumlahnya.

Definisi-definisi di atas telah sangat jelas memberikan informasi tentang apa saja isi di dalam sebuah kamus. Kosakata yang terdapat kamus, lazim disebut lema, disusun secara alfabetis yakni berurutan mulai A sampai Z. Tiap kata yang ditulis dilengkapi dengan cara pelafalannya, kelas kata, dan contoh pemakaian kata tersebut dalam sebuah kalimat.

Berikut ini adalah contoh salah satu kosakata yang terdapat dalam KBBI Pusat Bahasa Edisi Keempat, yaitu:

\section{ka.da.lu.war.sa $\rightarrow$ kedaluwarsa $(\mathrm{hlm}$.} 600)

ke.da.lu.war.saal tidak model lagi (baju, kendaraan, dsb); tidak sesuai dengan zaman: hakikat cerita itu telah -- apabila diajarkan sekarang; 2 sudah lewat (habis) jangka waktunya (tt tuntutan dsb); habis tempo; 3 terlewat dr batas waktu berlakunya sebagaimana yg ditetapkan (tt makanan); jika dimakan, makanan $y g$-- akan membahayakan kesehatan(hlm. 646)

Berdasarkan kutipan di atas, pada KBBI halaman 600, terdapat kata kadaluwarsa yang setelahnya diberikan simbol berupa tanda panah $(\rightarrow)$ menunjuk pada kata kedaluwarsa. Simbol tanda panah yang digunakan setelah kata kadaluwarsa menunjukkan bahwa kata tersebut bukanlah kata yang baku. Pembaca kamus diminta melihat makna kata yang ditunjuk oleh tanda panah tersebut. Kata yang ditunjuk tanda panah berarti merupakan kata yang dianggap baku. Pada kata kadaluwarsa, pembaca kamus diminta melihat kata kedaluwarsa.

Huruf a yang ditulis setelah kata kedaluwarsa menunjukkan kelas kata. Dalam hal ini, a berarti adjektifa (kata sifat). Nomor $\mathbf{1}, \quad \mathbf{2}$, dan $\mathbf{3}$ menginformasikan makna-makna yang dikandung dalam kata kedaluwarsa. Lalu kalimat yang dicetak miring 
menunjukkan contoh penggunaan kata tersebut (kata kedaluwarsa) dalam sebuah kalimat. Pembaca kamus dapat menyisipkan kata kedaluwarsa pada simbol "--' yang terdapat dalam contoh kalimat yang diberikan.

Kata besar yang terdapat dalam judul kamus bukanlah mengacu pada ukuran kamus secara fisik melainkan pada banyaknya informasi yang terdapat dalam kamus tersebut. Kamus besar adalah kamus yang mencatat kekayaan suatu bahasa sampai pada waktu tertentu, yang disusun dalam bentuk lema atau entri, lengkap dengan nuansa maknanya. Nuansa makna kata diuraikan dalam bentuk definisi, deskripsi, contoh, sinonim, atau parafrasa (KBBI, 2008:xxv)

Pada tahun 1952 Lembaga Penyelidikan Bahasa dan Kebudayaan Universitas Indonesia (instansi yang kemudian menjadi Pusat Bahasa) menerbitkan Kamus Umum Bahasa Indonesia oleh W.J.S. Poerwadarminta. Kamus tersebut merupakan tonggak sejarah dalam perkembangan leksikografi di Indonesia. Sebelum tahun 1976 kamus itu sudah mengalami cetakan ke-4 dan pada tahun yang sama terbit cetakan ke-5.

Pada Kongres Bahasa Indonesia V pada 28 Oktober 1988 di Jakarta diterbitkanlah Kamus Besar Bahasa Indonesia. Kamus tersebut merupakan hasil karya tim yang dipimpin oleh Kepala Pusat Bahasa, Anton M. Moeliono. Dengan berbagai pertimbangan dan masukan, Pusat Bahasa segera menerbitkan kembali Kamus Besar Bahasa Indonesia Edisi Kedua. Kemudian pada 2001 diterbitkan Kamus Besar Bahasa Indonesia Edisi Ketiga. Selanjutnya bahasa Indonesia mengalami perkembangan yang pesat sehingga pada 2008 diterbitkan Kamus Besar Bahasa Indonesia Edisi Keempat dengan penambahan nama lembaga pada judul kamus menjadi Kamus Besar Bahasa Indonesia Pusat Bahasa Edisi Keempat.

\section{b. Pembelajaran}

Pembelajaran pada hakikatnya merupakan penyediaan sistem lingkungan yang mengakibatkan terjadinya proses belajar pada diri siswa dengan mengoptimalkan potensi yang ada pada diri siswa tersebut.

Dalam UU No. 20/2003 Pasal 1 Ayat 20 tentang sistem pendidikan nasional diuraikan bahwa pembelajaran adalah proses interaksi peserta didik dengan pendidik dan sumber belajar pada suatu lingkungan belajar.

$$
\text { Apa yang dijelaskan oleh }
$$
Wikipedia pun tentang apa itu pembelajaran mengacu pada konsep di atas. Pembelajaran adalah proses interaksi peserta didik dengan pendidik dan sumber belajar pada suatu lingkungan belajar (https://id.wikipedia.org/wiki/).

Pembelajaran merupakan bantuan yang diberikan pendidik agar dapat terjadi proses perolehan ilmu dan pengetahuan, penguasaan kemahiran dan tabiat, serta pembentukan sikap dan kepercayaan pada peserta didik. Dengan kata lain, pembelajaran adalah proses untuk membantu peserta didik agar dapat belajar dengan baik.

Oemar Hamalik (239:2006) pembelajaran adalah suatu kombinasi yang tersusun meliputi unsur-unsur manusiawi, material fasilitas, perlengkapan, dan prosedur yang saling mempengaruhi tercapainya tujuan pembelajaran. Dari teori-teori yang dikemukan para ahli tentang konsep pembelajaran, Oemar Hamalik mengemukakan tiga rumusan, yaitu: 
1. Pembelajaran adalah upaya mengorganisasikan lingkungan untuk menciptakan kondisi belajar bagi peserta didik

2. Pembelajaran adalah upaya mempersiapkan peserta didik agar menjadi masyarakat yang baik

3. Pembelajaran adalah suatu proses membantu siswa menghadapi kehidupan masyarakat sehari-hari

Dapat disimpulkan bahwa pembelajaran adalah proses interaksi peserta didik dengan pendidik dan sumber belajar pada suatu lingkungan belajar demi tercapainya sebuah tujuan.

Pembelajaran yang berkualitas sangat tergantung dari motivasi pelajar dan kreativitas pengajar. Pembelajar yang memiliki motivasi tinggi ditunjang dengan pengajar yang mampu memfasilitasi motivasi tersebut akan membawa pada keberhasilan pencapaian target belajar. Target belajar dapat diukur melalui perubahan sikap dan kemampuan siswa melalui proses belajar.

$\begin{array}{cccc} & \text { Agar proses dan hasil belajar } \\ \text { dapat } & \text { sejalan } & \text { dengan tujuan }\end{array}$ pembelajaran, guru dituntut untuk dapat mendesain sebuah program pembelajaran yang menarik, salah satunya adalah dengan menggunakan sumber belajar yang tidak monoton.

Sumber belajar yang dapat digunakan dalam materi kosakata baku dan tidak baku pada kelas VI SD adalah KBBI. KBBI dapat digunakan secara berkelompok dengan arahan dan bimbingan guru.

\section{c. Kosakata Baku dan Tidak Baku}

Dalam KBBI Edisi Keempat disebutkan pengertian baku adalah pokok, utama; tolok ukur yang berlaku untuk kuantitas dan kualitas yang ditetapkan berdasarkan kesepakatan; standar.
Sementara menurut Kosasih dan Hermawan (2012:83) kata baku adalah kata yang cara pengucapan ataupun penulisannya sesuai dengan kaidahkaidah yang dibakukan. Kaidah standar yang dimaksud dapat berupa pedoman ejaan (EYD), tata bahasa baku, dan kamus.

Kata baku digunakan dalam konteks ragam baku, baik lisan maupun tulisan. Sementara kata tidak baku digunakan dalam ragam tidak baku.Ragam bahasa baku dapat dibatasi dengan beberapa sudut pandang, di antaranya: (1) sudut pandang kebakuan bahasa yang digunakan, (2) sudut pandang informasi, dan (3) sudut pandang pengguna bahasa.

Berdasarkan sudut pandang kebakuan bahasa, bahasa baku adalah bahasa yang baik tata tulis, kosakata, maupun tata bahasanya sesuai dengan hasil pembakuan bahasa. Dari sudut pandang informasi, bahasa baku adalah ragam bahasa yang digunakan dalam berkomunikasi tentang ilmu pengetahuan. Lalu berdasarkan sudut pandang pengguna bahasa, ragam bahasa baku dapat dibatasi dengan ragam bahasa yang lazim digunakan oleh penutur yang paling berpengaruh, seperti ilmuan, pemerintah, tokoh masyarakat, dan kaum jurnalis atau wartawan. Bahasa merekalah yang dianggap ragam bahasa baku (Mulyono dalam Chaer,2011:5).

Berdasarkan definisi-definisi di atas dapat disimpulkan bahwa kata baku adalah kata-kata yang lazim digunakan dalam situasi formal atau resmi yang penulisannya sesuai dengan kaidah-kaidah yang dibakukan. Baku tidaknya sebuah kata dapat dilihat dari segi lafal, ejaan, gramatika, dan kenasionalan-nya (Chaer,2011:131).

Menurut Moeliono dalam Chaer (2011:131) lafal baku bahasa Indonesia adalah lafal yang tidak menampakkan 
lagi ciri-ciri bahasa daerah atau bahasa asing seperti contoh berikut:

$\begin{array}{ll}\text { Tidak Baku } & \text { Baku } \\ \text { rapet } & \text { rapat } \\ \text { cuman } & \text { cuma } \\ \text { dudu' } & \text { duduk } \\ \text { gubug } & \text { gubuk }\end{array}$

Lalu baku dari sudut pandang ejaan berarti semua kata yang tidak ditulis menurut kaidah yang diatur dalam EYD adalah kata yang tidak baku. Sementara yang ditulis sesuai dengan aturan EYD adalah kata yang baku.

\section{Contoh:}

TidakBaku

Ekpres

komplek

$\begin{array}{ll}\text { do'a } & \text { doa } \\ \text { jum'at } & \text { Jumat }\end{array}$

Secara gramatikal kata-kata baku ini harus dibentuk menurut kaidahkaidah gramatika. Perhatikan katakata ngontrak, sekolah, tinjau, kedudukk an, dan bikin bersih pada kalimatkalimat berikut!

(1) Beliau ngontrak rumah di Cilandak

(2) Seorang ibu sedang urus KJP anaknya

(3) Rumah ini akan dikontrakan

(4) Tolong bikin rapi kelas ini

Bentuk baku kata ngontrak pada kalimat (1) adalah mengontrak. Bentuk baku kata urus adalah kata mengurus; sebuah awalan me- harus digunakan secara konsisten. Bentuk baku kata dikontrakan adalah dikontrakkan (dua k). Lalu, bentuk baku kata bikin rapi adalah rapikan.

Kata-kata yang masih bersifat kedaerahan juga termasuk kosakata tidak baku. Contohnya:

Tidak Baku

Baku

$\begin{array}{ll}\text { lempeng } & \text { lurus } \\ \text { ndak,nggak } & \text { tidak } \\ \text { banget } & \text { sekali,sang } \\ \text { semrawut } & \text { kacau } \\ \text { manut } & \text { menurut }\end{array}$

Kata serapan dari bahasa asing disebut baku kalau ejaannya telah dibuat menurut pedoman penyesuaian ejaan bahasa asing seperti yang disebutkan dalam EYD maupun dalam buku Pedoman

Istilah (Depdikbud

Pembentukan

Chaer,2011:134).

$\begin{array}{cc}\text { TidakBaku } & \text { Baku } \\ \text { standard } & \text { standar } \\ \text { standarisasi } & \\ \text { standardisasi } & \\ \text { kolektip } & \text { kolektif } \\ \text { certifikat } & \text { sertifikat } \\ \text { analisa } & \text { analisis }\end{array}$

Berikut adalah beberapa contoh kosakata baku dalam KBBI yang dapat disosialisasikan kepada siswa:

\begin{tabular}{|c|c|c|c|}
\hline \multirow[t]{2}{*}{$\begin{array}{l}\mathbf{N} \\
\mathbf{o}\end{array}$} & \multicolumn{2}{|c|}{$\begin{array}{c}\text { Contoh Kosakata } \\
\text { dalam KBBI }\end{array}$} & \multirow[t]{2}{*}{ Keterangan } \\
\hline & $\begin{array}{l}\text { Tidak } \\
\text { Baku }\end{array}$ & Baku & \\
\hline 1 & Apotik & Apotek & $\begin{array}{l}\text { Toko tempat } \\
\text { meramu dan } \\
\text { menjual obat } \\
\text { berdasarkan } \\
\text { resep dokter } \\
\text { serta } \\
\text { memperdagangk } \\
\text { an barang medis; } \\
\text { rumah obat }\end{array}$ \\
\hline 2 & Astana & Istana & $\begin{array}{l}\text { Rumah } \\
\text { kediaman resmi } \\
\text { raja (kepala } \\
\text { negara, } \\
\text { presiden) dan } \\
\text { keluarganya } \\
\end{array}$ \\
\hline 3 & Beludru & Beledu & $\begin{array}{l}\text { Kain dengan } \\
\text { permukaan yang } \\
\text { tebal, berbulu } \\
\text { halus pada } \\
\text { bagian depan } \\
\text { dan rata pada }\end{array}$ \\
\hline
\end{tabular}




\begin{tabular}{|c|c|c|c|}
\hline & & & $\begin{array}{l}\text { bagian belakang, } \\
\text { lembut, berkilat, } \\
\text { sering dibuat } \\
\text { kopiah atau baju } \\
\text { kebesaran }\end{array}$ \\
\hline 4 & Coklat & Cokelat & $\begin{array}{l}\text { Bubuk dari biji } \\
\text { cokelat; gula- } \\
\text { gula yang dibuat } \\
\text { dari } \\
\text { cokelat; merah } \\
\text { kehitam-hitaman } \\
\text { seperti warna } \\
\text { sawo matang }\end{array}$ \\
\hline 5 & Hutang & Utang & $\begin{array}{lr}\text { Uang } & \text { yang } \\
\text { dipinjam } & \text { dari } \\
\text { orang } & \text { lain; } \\
\text { kewajiban } & \\
\text { membayar } & \\
\text { kembali apa } & \\
\text { telah diterima }\end{array}$ \\
\hline 6 & Kate & Katai & $\begin{array}{l}\text { Kecil atau kerdil } \\
\text { pertumbuhannya }\end{array}$ \\
\hline 7 & Kawatir & Khawatir & $\begin{array}{l}\text { Takut (gelisah, } \\
\text { cemas) terhadap } \\
\text { suatu hal yang } \\
\text { belum diketahui } \\
\text { dengan pasti }\end{array}$ \\
\hline 8 & Kwartet & Kuartet & $\begin{array}{l}\text { Kelompok, } \\
\text { kumpulan, dan } \\
\text { sebagainya yang } \\
\text { terdiri atas } \\
\text { empat; } \\
\text { komposisi musik } \\
\text { yang terdiri atas } \\
\text { empat } \\
\text { instrument }\end{array}$ \\
\hline 9 & Lahat & Lahad & $\begin{array}{l}\text { Ceruk atau } \\
\text { relung di lubang } \\
\text { kubur tempat } \\
\text { meletakkan } \\
\text { mayat }\end{array}$ \\
\hline 10 & Materai & Meterai & $\begin{array}{l}\text { Cap tanda } \\
\text { berupa gambar } \\
\text { yang tercantum } \\
\text { pada kertas atau } \\
\text { terukir pada } \\
\text { kayu, besi, dsb; } \\
\text { cap; tera;.segel }\end{array}$ \\
\hline 11 & Meleset & Peleset & $\begin{array}{lr}\text { Tidak mengenai } \\
\text { sasaran; } & \text { tidak } \\
\text { mengenai } & \text { yang } \\
\text { dituju } & \\
\end{array}$ \\
\hline 12 & Milyar & Miliar & Seribu juta \\
\hline 13 & Nampak & Tampak & $\begin{array}{l}\text { Dapat dilihat, } \\
\text { kelihatan }\end{array}$ \\
\hline 14 & Nakoda & Nakhoda & $\begin{array}{l}\text { Juragan } \\
\text { (pemimpin) }\end{array}$ \\
\hline
\end{tabular}

\begin{tabular}{|l|l|l|l|}
\hline & & & $\begin{array}{l}\text { perahu (kapal); } \\
\text { perwira laut } \\
\text { yang memegang } \\
\text { komando } \\
\text { tertinggi di atas } \\
\text { kapal niaga; } \\
\text { kapten kapal }\end{array}$ \\
\hline 15 & $\begin{array}{l}\text { Pamungk } \\
\text { as }\end{array}$ & $\begin{array}{l}\text { Pemungk } \\
\text { as }\end{array}$ & $\begin{array}{l}\text { Yang terakhir, } \\
\text { yang } \\
\text { menimbulkan } \\
\text { kematian }\end{array}$ \\
\hline 16 & Rubah & Ubah & $\begin{array}{l}\text { Tukar, ganti } \\
\text { Taat dan } \\
\text { sungguh- } \\
\text { sungguh } \\
\text { menjalankan } \\
\text { ibadah }\end{array}$ \\
\hline 17 & Salih & Saleh & Pesohor \\
\hline 18 & Selebritis & Selebritas & $\begin{array}{l}\text { Berhenti; } \\
\text { terhenti }\end{array}$ \\
\hline 19 & Stop & Setop & $\begin{array}{l}\text { Hari ke-2 dalam } \\
\text { jangka waktu } \\
\text { satu minggu }\end{array}$ \\
\hline 20 & Senen & Senin &
\end{tabular}

\section{Simpulan}

Pembelajaran adalah proses interaksi peserta didik dengan pendidik dan sumber belajar pada suatu lingkungan belajar demi tercapainya sebuah tujuan. Agar proses dan hasil belajar dapat sejalan dengan tujuan pembelajaran, guru dituntut untuk dapat mendesain sebuah program pembelajaran yang menarik, salah satunya adalah dengan menggunakan sumber belajar yang tidak monoton.

Kamus Besar Bahasa Indonesia adalah salah satu sumber belajar yang dapat digunakan siswa dan guru dalam pembelajaran kosakata baku dan tidak baku. Kamus adalah sebuah karya yang berfungsi sebagai referensi. Kamus pada umumnya berupa senarai kata yang disusun secara alfabetis. Selain itu, disertakan pula informasi mengenai ejaan, pelafalan, kelas kata, makna kata, kadangkala sejarah kata, dan contoh pemakaian kata dalam kalimat

Kata baku adalah kata-kata yang lazim digunakan dalam situasi formal atau resmi yang penulisannya sesuai 
dengan kaidah-kaidah yang dibakukan. Baku tidaknya sebuah kata dapat dilihat dari segi lafal, ejaan, gramatika, dan kenasionalan-nya. Pengetahuan tentang kosakata baku akan sangat membantu siswa bukan hanya dalam mata pelajaran bahasa Indonesia melainkan juga dalam pelajaran lain.

\section{Daftar Rujukan}

Alwi, Hasan dkk. (2000). Tata Bahasa Baku Bahasa Indonesia Edisi Ketiga. Jakarta: Balai Pustaka.

Arifin, E. Zaenal dkk. (2014). Pengembangan dan Pembinaan Bahasa pada Era Teknologi Informasi. Jakarta: Pustaka Mandiri (Penerbit Buku Super).

Chaer, Abdul. (2011). Kesantunan Berbahasa. Jakarta: Rineka Cipta.

Departemen Pendidikan Nasional. (2008). Kamus Besar Bahasa Indonesia Pusat Bahasa Edisi Keempat. Jakarta: Gramedia Pustaka Utama.
Depdikbud. Kurikulum 2013 untuk Sekolah Dasar

Hamalik, O. (2006). Proses Belajar Mengajar. Bandung: Bumi Aksara.

https://id.wikipedia.org/wiki/. Diunduh pada 23 Maret 2016.

Kosasih, E. dan Hermawan, Wawan. (2012). Bahasa Indonesia Berbasis Kepenulisan Karya Ilmiah dan Jurnal. Bandung: Thursina.

Kushartanti dkk. (2009). Pesona Bahasa: Langkah Awal Memahami Linguistik. Jakarta: Gramedia Pustaka Utama.

Nazir, M. (2005). Metode Penelitian. Jakarta: Ghalia Indonesia.

Tim Penyusun. (2007). Pedoman Umum Ejaan Bahasa Indonesia yang Disempurnakan. Yogyakarta: Indonesiatera. 